\title{
Aesthetic Expression Of Chinese Elements In Modern Women's Clothing
}

\author{
QingHui Peng \\ JiangXi Institute Of Fashion Technology \\ NanChang China \\ victor-peng@yeah.net
}

Keywords: Chinese style; Aesthetics; Performance; Elements; combine

\begin{abstract}
The Chinese elements in the field of modern women's clothing design has always been a kind of inspiration source the designer likes. Exploring and excavating Chinese elements of different aesthetic value can provide a new design direction for designers, and then create a new clothing styles and aesthetic concept. The aesthetic value in Chinese elements according to the definition and classification can be divided into three kinds that are pure Chinese, the Chinese in western and Chinese-western aesthetic expression. These three kinds of aesthetic values lead to three different design methods in modern women's clothing which immits the cultural connotation and the spiritual symbol into the Chinese style dress.
\end{abstract}

\section{CHINESE ELEMENTS OVERVIEW}

The so-called Chinese elements, in general terms, are able to be reflected with the elements of Chinese characteristics. From the perspective of fashion designers, the category of Chinese elements have no boundary. The materials which can provide inspiration for designers, and have the characteristics of Chinese culture or Chinese spiritual can be called with Chinese style design elements.

Chinese elements have much varieties. The crossover design is popular in modern design. A fashion designer can seek inspiration from what has Chinese style of architecture for the clothing design in crossover design. Finding inspiration for the design from the building can also be used in the Chinese style clothing. According to the inspiration source in the design of clothing, the Chinese elements in the clothing design in accordance with the shape feature can be divided into two major categories, which are figurative elements and abstract elements.

Representational element contains all entities and have a certain style in inspiration origin. It can be everywhere in the unique things of all aspects in everyday life, such as Chinese style of architecture, product design, patterns, characters, animals and plants, etc. It can also be extracted from various cultural fields of typical things. For example, the calligraphy, Chinese painting, Beijing Opera, Chinese zither, face drawing, shadow play, blue and white porcelain from sisters art, etc. Those things are very typical Chinese quintessence, and there are specific characteristics forms. Designers choose the design inspiration from those elements and develop the clothing product after upgrading them a little. It is necessary to dig deep cultural background and development process of the element to design a high level of clothing products, which can be changeful in the hands of designers.

Abstract elements is the design element that can reflect Chinese culture and spirits, such as the culture of Taoism, Confucianism spirit, strength in calligraphy, intangible in traditional Chinese painting, artistic conception in tea culture, and so on. They are abstract elements in China which are difficult to control in representational element extraction and to be used in design. To use the medium to express their own clothing element extracted Chinese abstract concepts, designers should not only express the element of artistic conception and the charming performance in the clothing, but also should be enable the wearer to feel the designers idea. Finally, when showing the viewer can understand it, even resonate it. Then it can be called an outstanding clothing design work. That clothing designers extract the design elements from the design thinking to express design concept can be called success.

According to the cultural characteristics from different fields, the Chinese elements can also be divided into direct and indirect element. Direct element is that is extracted with Chinese characteristics from clothing design elements in direct, such as Chinese national costumes and folk 
costumes, such as hanfu, tang suit, cheongsam and other minority costumes in Chinese national dress. And the folk costumes lies in regional costumes culture, such as cotton-padded jacket in northeast of China and Yunnan batik clothing. Indirect element is the design element that contains the Chinese characteristics design elements in other sisters art. According to the different forms and standards to define the Chinese elements, they can be divided into various categories. No matter how to divide and definition, the aesthetic value in those elements will not be changed in the history of Chinese culture and the essence of them is pure. Using the Chinese elements as the inspiration for fashion design leads to the final work which will has the characteristics of Chinese culture in the beginning of inspiration choice. This feature has it own uniqueness which is different from other works, that is why fashion designers constantly blaze new trails in this field with enthusiasm.

\section{EXPRESSION AND AESTHETIC VALUE OF CHINESE ELEMENTS IN THE MODERN WOMEN'S CLOTHING}

Orthodox Aesthetic Expression of Pure Chinese Style. Pure Chinese style refers to the clothes which are pure and which is completely made by Chinese elements without other elements which can confuse them, which will show Chinese style.

For example, cheongsam which has always been a place in the modern women's clothing. Cheongsam itself belongs to one of the Chinese traditional national costumes. But because of the aesthetic value of cheongsam, the modern women in the consumers still like it. So in a lot of Chinese style dress brand, improved cheongsam clothing products often can be seen. In traditional Chinese style dress brand, cheongsam with classic is the NO.1 choice for the bride in Chinese weddings, too.

Professor Bian Xiangyang mentioned in his paper The Origin of the Popularity of Cheongsam: the cheongsam is the one piece dress, meanwhile, it must have all or part of prominent typical exterior characterization: open or half-open form of right lapel, stand collar with button and splitting in side of details, single Piece of cloth, garment body even the sleeve plane cutting, etc. In spite of that the Chinese dress contains robe in Qing Dynasty and the Republic of China, usually in the sense of cheongsam, it generally refers to the dress that in the Republic of China of the $20^{\text {th }}$ century." During the period of the Republic of China in the $20^{\text {th }}$ century, Chinese dress style and the traditional aesthetic orientation of men's wearing showed the contrast. It had S profile type of joint human body, a system of segmentation lines cutting out of the way made the clothing styles be longitudinal extension on the whole. There was no horizontal lines that reduced truncation feeling, so that it seemed to have long slender dress after of human body. This version of the type of clothing can to a great degree highlights women fruity body curve and emphasizes the women's traditional characteristics. And the traditional aesthetic in men's wearing with strength for the mainstream values. In order to show the strength, men's clothing line was designed in the structure and decorative thread which was mostly in a straight line. And the collar and buttons of cheongsam profile are the detail design, such as fork from the structure line and line of the decoration which is mostly with curve. The analysis concludes that Qipao is to orthodox aesthetic reflecting the concept of the first design itself which has very orthodox women dress after a kind of aesthetic feeling, and soft feeling. Secondly, after the Chinese women wearing cheongsam, the image recognition is very high. During the period of the Republic of China, Chinese dress was very popular. In the eyes of foreigners, Chinese women at that time were one of the most typical images with delicate small volume of marcel collocation gorgeous in colorful cheongsam. This cognition was what they brought home, which had left its traces in the western costume culture cognition.

As time passing by, although the Chinese dress is no longer a main style of the everyday wearing of modern women, as one of the design of high recognition of Chinese style dress, Chinese dress took its own place in women's wardrobe mediator. And, it contains the meaning of being modern people into a whole new level. For example, in 2008, China hold the Olympic Games, Chinese dress was taken as the hostesses dress. The winning design is the improved cheongsam style. In 2014, at the $22^{\text {nd }}$ APEC meeting in Beijing, cheongsam was also ultimately chosen as the leader ladies clothing. Thus, cheongsam of orthodox made it be with the classical aesthetic concept. The beauty of this classical cheongsam does not change over time, but became the representative and the cognition for Chinese female aesthetic style in the national costume culture.

For the West in the Traditional Aesthetics. Chinese designers using Chinese elements for women's clothing design can show more purely Chinese style concept. Western designers using 
Chinese style element design ladies will show a kind of Chinese style style. As a result, the difference is caused by the differences between the designers of Chinese and the western culture. In 2011 Paris fashion of Louis vuitton, Zhou Chunxia series used the folding fan, Qipao, panda beaded and tassel and other Chinese elements.These elements which were classical and elegant. And Louis vuitton innovation boldly made Qipao be a bump color. Split up to the waist line. The panda's beaded pattern was witty and lively. With blond hair style, the western model throughout the show was novel and very sexy. This style of Chinese elements using the novel technique is unique, which is good to meet the psychological needs of consumers to the pursuit of new things. Subversive using design elements makes a design element deviated from the original aesthetic form, which shows a new aesthetic attitude, which is public perception of novel, unique cognition of niche. Concept popularized becomes popular. After the public cognition of popular beauty of non-mainstream, there is no alternative beauty and modern beauty. And small begins to pursue other to more novelty to another to meet their psychological changes. So there are a lot of clothing styles and design of the concept of the traditional aesthetics. The starting point of designers is to create them in part because of the pursuit of better creation, on the other hand, because of curiosity demand caused by consumers. Although no mainstream aesthetic is an aesthetic style, all sorts of little is against the traditional aesthetic concept. Designers seek to breakthrough their own images. In contrast to their existence and orthodox aesthetic concept, modern women's clothing has formed a variety of styles.

The Combination of Chinese and Western Modern Aesthetics. The application of Chinese elements in modern women's clothing design technique in addition to the purely Chinese style and western style is a fusion of Chinese and western to reflect the contemporary mainstream women's aesthetic design gimmick. From the point of view of the concept, this technique is similar to the west with design gimmick. But between the two, there are essential difference. The western methods focus on a westernized Chinese elements, finally making it show the aesthetic feeling of a western style. Seeing from the vision which has changed the element itself, it has the beauty of Chinese culture. The aesthetic difference between the mass aesthetic standards can accept the cognition to the United States, which cannot accept the willing of cognition as bizarre. And the design methods of combination of Chinese and western is reserved aesthetic trait of Chinese elements itself, and then through the reasonable proportion distribution of Chinese and western elements, blend together. This technique designed dress can be able to reflect a harmonious aesthetic feeling no matter which country people wear. So the combination of Chinese and western design methods can be more accepted by the public, therefore has become now a mainstream design gimmick.

For example, the most commonly seen type of dragon in Chinese elements can be seen everywhere in the Forbidden City which is a white marble carving dragon. WuLongDeng of Spring Festival and the Dragon Boat Festival dragon boat racing is the image of dragon and concept until now. The dragon is one of China's han nation advocating god beasts. In Chinese traditional culture, dragon has two bifurcation angles, snake body, four legs and whole body scales. Then the dragon evolves as a symbol of the supreme power in Chinese culture, and becomes the representative of the emperor. So in ancient times, the emperor after wearing costumes embroidered dragon pattern was called the "dragon robe. The supreme, unassailable power maked the image of dragon awe in the hearts of people. Awe in the clothing of the aesthetic value showed strong and gorgeous clothing style. Fan Bingbing who wore yellow dragon dress on the red carpet at Cannes Film Festival was to use the design methods of combination of Chinese and western to complete the work. Designers completely kept the aesthetic value of dragon culture in China. Pattern design of the atmosphere was supplemented by contracted and fluent fishtail skirt profile. Chinese grain appearance was given priority to, western models was complementary. The proportion of balanced type distribution made the design of the dress be outstanding, primary and with secondary distinct style.

\section{Conclusion}

Modern women choose different styles of dresses to express themselves. Each kind of clothing style aesthetic concept shows appreciation of its wearer. It can be seen by analysis, the aesthetic feeling of Chinese elements is diverse and characteristic. A single Chinese style change actually extends out a 
variety of different aesthetic feeling. Simple straightforward design methods emphasizing shape can show the aesthetic charm of traditional Chinese culture. Design methods emphasize spirit likeness, to Chinese elements of the cultural connotation to the spirit level, raising the cultural value of the clothing. The use of Chinese elements to modern women's clothing design makes these elements in the clothing of the changes in the media. Especially now many designers prefer to mix design technique to design clothing, the use of different proportion of design elements will also be for other elements of the nature of mutual fusion and produce a new aesthetic value.

In today's women's clothing T stage, the situation of flowers have already opened. Prospects of the development of the modern women's clothing is somewhat not the Chinese traditional culture, the tributaries ancestors legacy of material culture and non-material cultural heritage should not be only used for later viewing, they should go abroad to become the spiritual and cultural symbol of the Chinese nation, to become the world's aesthetic culture, which is the most moving one page.

\section{References}

[1] BianXiangYang Theory of origin of the popularity of cheongsam. "decoration",November 2003

[2] Chen Jingyu The modern women's clothing design elements.[ academic dissertation] Donghua university,2004

[3] Liu Xiaoping In traditional Chinese costume culture element in modern clothing modelling application. Journal of Shaoyang University,April 2011

[4] Yan Fengling Shallow discussion now Chinese elements in modern fashion design. the Yalu River, February2015

[5] YuYing The application of Chinese elements in the clothing design .Journal of anhui textile vocational technology college, September2002

[6] Chen Jingyu The modern women's clothing design elements. Donghua university, master's thesis,January 2004

[7] Li Yang Traditional Chinese painting in the application of custom clothing design element. Master thesis, Beijing institute of fashion technology, December2012

[8] Wei Caijie The theory of creative Chinese elements in the design of the road to modernization. $\langle$ Grain in ear $\rangle$ 420th

[9] Xie Julan Traditional national culture and modern "mixed". Social Sciences Review,June 2004

[10]Ye Lang Aesthetic theory[M]. Peking University Press,2009.Beijing

[11]Huang Shilong Overview of modern clothing culture[M]. Donghua university press, 2009. Shanghai

[12]Wu Weigang Clothing aesthetic. China's textile press,2000.Beijing. 